\title{
Porf-2 $=$ Arhgap39 $=$ Vilse: A Pivotal Role in Neurodevelopment, Learning and Memory
}

\author{
Felicia V. Nowak
}

https://doi.org/10.1523/ENEURO.0082-18.2018

Department of Biomedical Sciences, Diabetes Institute and Program in Molecular and Cellular Biology, Ohio University, Athens, OH 45701

\begin{abstract}
Small GTP-converting enzymes, GTPases, are essential for the efficient completion of many physiological and developmental processes. They are regulated by GTPase activating proteins (GAPs) and guanine nucleotide exchange factors (GEFs). Arhgap39, also known as preoptic regulatory factor-2 (Porf-2) or Vilse, a member of the Rho GAP group, was first identified in 1990 in the rat CNS. It has since been shown to regulate apoptosis, cell migration, neurogenesis, and cerebral and hippocampal dendritic spine morphology. It plays a pivotal role in neurodevelopment and learning and memory. Homologous or orthologous genes are found in more than 280 vertebrate and invertebrate species, suggesting preservation through evolution. Not surprisingly, loss of the Arhgap39/Porf-2 gene in mice manifests as an embryonic lethal condition. Although Arhgap39/Porf-2 is highly expressed in the brain, it is also widely distributed throughout the body, with potential additional roles in oncogenesis and morphogenesis. This review summarizes, for the first time, the known information about this gene under its various names, in addition to considering its transcripts and proteins. The majority of findings described have been made in rats, mice, humans, and fruit flies. This work surveys the known functions, functional mediators, variables modifying expression and upstream regulators of expression, and potential physiological and pathological roles of Arhgap39/Porf-2 in health and disease.
\end{abstract}

Key words: Apoptosis; Arhgap39; dendritic spines; learning and memory; Porf-2; RhoGAP

\section{Significance Statement}

This review comprehensively includes what is currently known about Arhgap39/Porf-2 under its multiple names. Arhgap39 is a critically required molecule for neurodevelopment, learning, and memory that is expressed throughout the lifespan. It also has definitive roles in stem cell fate and cell migration, apoptosis, and proliferation, in both neural and nonneural sites. Homologous or orthologous genes have been conserved for millennia through evolution with a wide phylogenetic distribution from invertebrates to mammals. Its expression is exquisitely regulated by age, sex, location, and hormones. The consequences of dysregulation of Arhgap39 are currently under investigation.

\section{Introduction}

\section{GTP-converting enzymes and their modifying proteins}

Small GTP-converting enzymes, GTPases, ranging in size from 20 to $40 \mathrm{KDa}$, are essential for the efficient

\footnotetext{
Received February 22, 2018; accepted August 8, 2018; First published September 14, 2018.

The author declares no competing financial interests.

Author contributions: FVN reviewed literature and wrote the paper.
}

completion of many physiologic and developmental processes (Peck et al., 2002; Moon and Zheng, 2003; Jiang and Ramachandran, 2006; Tcherkezian and LamarcheVane, 2007; De Filippis et al., 2014; Ghosh et al., 2017). The GTPases switch between an active GTP-bound state

Funding Source: Ohio University Faculty Fellowship Award.

Acknowledgments: The author acknowledges her colleagues, Pat O'Connor, $\mathrm{PhD}$, and Yuriy Slyvka, MD/PhD, for helpful suggestions and insightful comments. Many thanks as well to the students and collaborators who have 


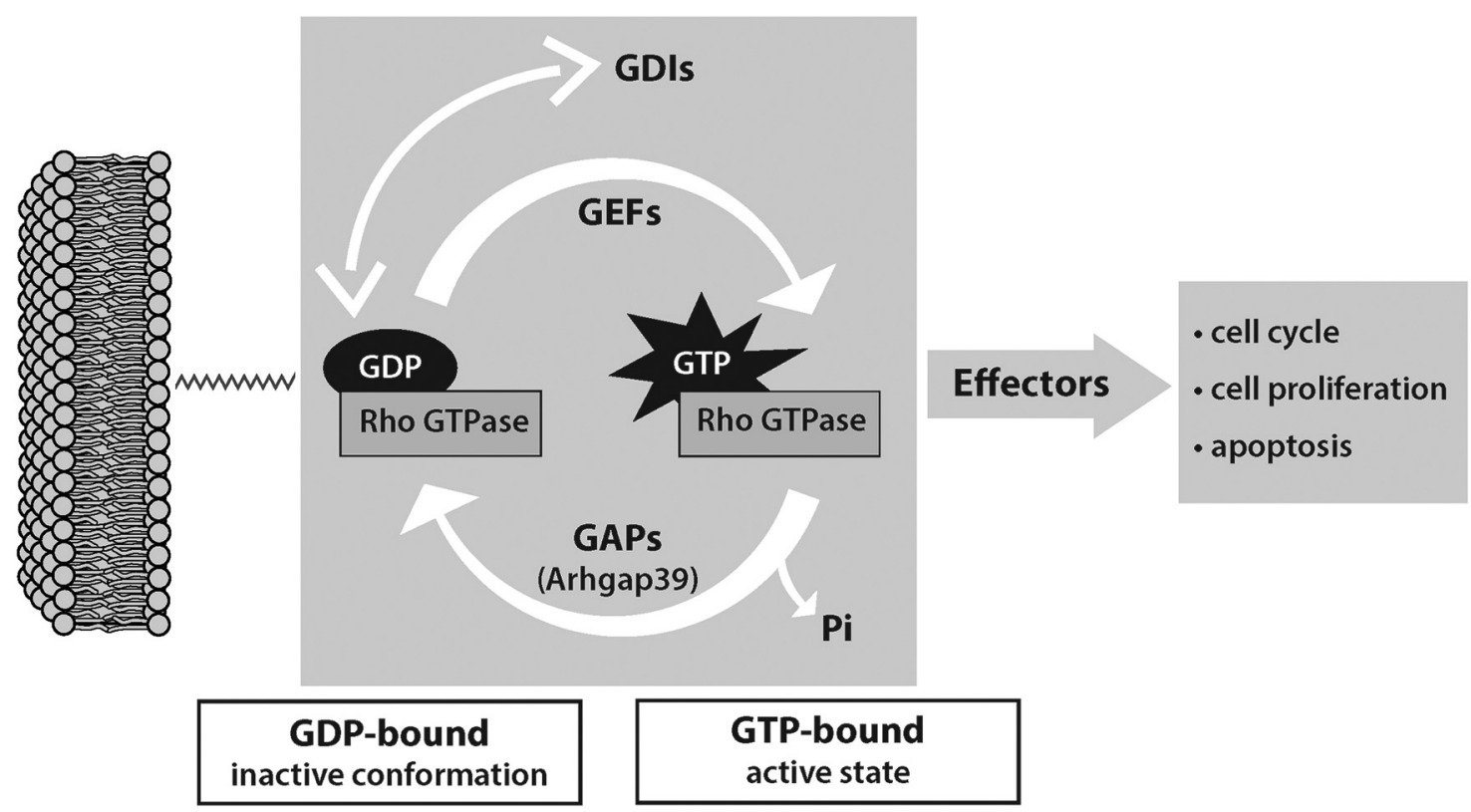

Figure 1. Schematic of Rac/Rho functional conversion, activation, and inactivation. GAP, GTPase activating protein; GDI, guanine nucleotide dissociation inhibitor; GEF, guanine nucleotide exchange factor; GTPase, guanine nucleotide triphosphate hydrolase.

and an inactive GDP-bound form as illustrated in Fig. 1. These switches are mediated by GTPase activating (or accelerating) proteins (GAPs) and guanine nucleotide exchange factors (GEFs). GEFs promote the binding of GTP, thus favoring the active state, while GAPs enhance the intrinsic activity of the GTPase, leading to GTP hydrolysis and returning the GTPase to an inactive state. Thus, GAPs can also be considered co-effectors with their GTPase partners. The inactive state is further promoted by guanine nucleotide dissociation inhibitors (GDIs), which sequester and stabilize the GDP-associated form.

There are five GTPase subfamilies: Ras (rat sarcoma), Rho (Ras homolog), Rab (rat brain), Arf/Sar (ADP-ribosylation factor/secretion-associated Ras-related protein), and Ran (Ras-related nuclear) in eukaryotes. These five subfamilies have been extensively studied in yeast, Arabidopsis, rice, Drosophila melanogaster, and selected vertebrates, especially rodents and humans (Jiang and Ramachandran, 2006; De Filippis et al., 2014; Yorimitsu et al., 2014). They regulate a diverse array of cellular functions, such as cytoskeletal reorganization, cell motility and polarity, vesicular trafficking, and cell fate and differ-

contributed to the work in the author's lab on the regulation and function of Arhgap39/Porf-2: Shuang Ma, PhD, Zhenchao Wang, MD/PhD, Jose Torres, MS, Shuang-Bao Hu, PhD, Jennifer Yee, DO, Shannon Gilham, DO, Kimberly Nemeth, DO, Ekokobe Fonkem, DO, Matthew Colpo, Jill Carlsen, Wenjuan Zhang, Christopher Pun, Andrea Gore, PhD, Jennifer Golden, MS, Gonzalo Torres, PhD, and Xinhao Liu, MD/PhD.

Correspondence should be addressed to Felicia V. Nowak, Department of Biomedical Sciences, 228 Irvine Hall, Ohio University, Athens, OH 45701. E-mail: nowak@ohio.edu.

https://doi.org/10.1523/ENEURO.0082-18.2018

Copyright (C) 2018 Nowak

This is an open-access article distributed under the terms of the Creative Commons Attribution 4.0 International license, which permits unrestricted use, distribution and reproduction in any medium provided that the original work is properly attributed. entiation. Each GTPase subfamily has an associated GAP subfamily. Several groups of Rho GTPases exist, including Rho, Rac, Cdc42, and Rnd. An individual RhoGAP can interact with several Rho GTPases, depending on the cellular and developmental context.

\section{A brief history of Arhgap39/Porf-2 discovery}

The first paper on Arhgap39/Porf-2 reported the partial sequence and tissue distribution of the messenger RNA in the rat (Nowak, 1990). Subsequently, the investigation of the physiology and regulation of Arhgap39/Porf-2 in the rat led to the publication of 11 peer-reviewed manuscripts, including a summary book chapter on the discovery and characterization of Porf-2 (Nowak, 2014). It was found that Arhgap39/Porf-2 proteins are encoded by multiple RNA transcripts with tissue-specific expression. Arhgap39/Porf-2 is highly expressed in mammalian brain, including hypothalamus (regulation of metabolism and reproduction) and hippocampus (essential for learning and memory; Nowak, 1990; Hu and Nowak, 1994). The pattern of hypothalamic expression in the preoptic areaanterior hypothalamus (POA-AH) during a critical period of prenatal development is sex specific, with levels peaking earlier in males [embryonic day 18 (E18)-E19] than in females [postnatal day 0 (P0); Nowak and Gore, 1999]. It was found that the hormones, estradiol (E2) and progesterone (P4), regulate its expression in the female rat brain (Nowak et al., 1999). In males, gonadotropic pituitary factors decrease Arhgap39/Porf-2 mRNA in the POA and in the testes (Nowak et al., 1997) and testicular factors decrease Arhgap39/Porf-2 mRNA in the POA, but not in the medial basal hypothalamus (MBH) or cerebral cortex. Through this work it was also learned that Arhgap39/ Porf-2 is highly expressed in a subset of immature germ cells in testes (Nowak et al., 1997). In sum, these results suggest that precise regulation of Arhgap39/Porf-2 ex- 
Table 1. Arhgap39/Porf-2 gene structure, RNA transcripts, and proteins

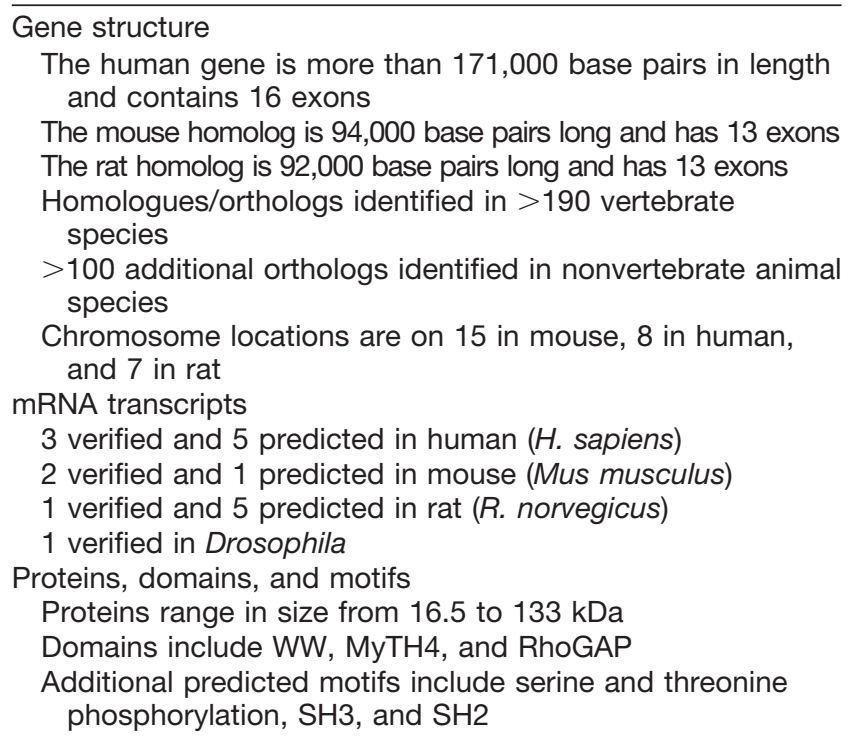

pression has an impact on both CNS development and reproductive health. Finally it was discovered, using Southern blot analysis, that Arhgap39/Porf-2-like genes were present in nine widely ranging groups of vertebrates including primates, ungulates, rodents, birds, and fish (Schmerr et al., 2002), but the functions of this gene remained elusive. For more detail, see Variables modifying expression and upstream regulators.

\section{Arhgap39/Porf-2-from EST to ORF}

Arhgap39/Porf-2, also known as Vilse, KIAA1688, D15Wsu169e, CrossGAP, and Rho GTPase activating protein39, is a RhoGAP protein. Its ortholog is known as Arhgap93B in Drosophila. Evidence that this gene contains a functional open reading frame (ORF) emerged slowly, initially based on a partial sequence (Nowak, 1990) from a rat brain cDNA library. Its existence was hinted at as a member of several expressed sequence tag (EST) collections (Ko et al., 1998; Miki et al., 2001; Okazaki et al., 2002), including pre-implantation mouse embryo (Ko et al., 2000), and orphan gene libraries (Bonaldo et al., 1996; Carninci et al., 2000). Arhgap39/Porf-2 has been identified in more than 20 large-scale comprehensive enumerations of genes expressed as RNA transcripts and proteins. The complete mouse coding sequence was predicted in 2001 (Kawai et al., 2001) and verified by Okazaki et al. (2004). The Arhgap39/Porf-2 story has emerged slowly from a series of studies that demonstrate regional, temporal, and physiologic variations in expression, tissue, and location, some of which likely reflect species-specific functional roles for this gene. These will be discussed in more detail below.

\section{Gene, RNA, and Protein (Table 1)}

\section{Phylogenetic distribution of Arhgap39/Porf-2}

In 2002, the first phylogenetic distribution analysis was reported for Arhgap39/Porf-2 (Schmerr et al., 2002).
Southern blot analysis using a rat probe revealed homologs in human, mouse, pig, sheep, cow, chicken (two bands), and zebrafish. It was shown that, in the rat, Arhgap39/Porf-2 is a single-copy gene (Nowak et al., 1997), and this has been confirmed in human and mouse with the sequencing of their complete genomes. In Drosophila, there is a single ortholog. However, the possibility remains that duplications have occurred in other species, including chickens.

In 2002, the Mammalian Gene Collection Program team identified murine Arhgap39/Porf-2 as a candidate fullORF clone (Strausberg et al., 2002). Subsequently, in 2004, the Mammalian Genome Project reported the fullORF cDNA sequences in mouse and human (Gerhard et al., 2004). In 2011, the mouse gene location was determined by the Jackson Laboratory (Bar Harbor, ME) to be on chromosome 15 (Diez-Roux et al., 2011). The gene is positioned on chromosome 7 in rats and on chromosome 8 in humans.

To date, 180 orthologs, identified by gene and exome sequencing, have been reported in a variety of vertebrate species, from platypuses (https://www.ncbi.nlm.nih.gov/ gene/103168041) to equids (Hestand et al., 2015) and penguins (https://www.ncbi.nlm.nih.gov/gene/103901269). Moreover, the homologous mouse and human genes are located in a large conserved syntenic region corresponding to human chromosome 8 and mouse chromosome 15, supporting derivation from a common ancestor that existed at minimum 75 million years ago (Mouse Genome Sequencing Consortium et al., 2002). A related gene (Arhgap93B) in Drosophila and other invertebrates has now been identified in $>100$ additional species. As the common ancestor of vertebrates and insects existed at minimum $\sim 530$ million years ago, this raises the possibility that Arhgap39/Porf-2 is even older, but this idea remains to be rigorously evaluated.

\section{DNA and RNA structure and modifications}

The mouse Arhgap39/Porf-2 gene is $\sim 94,000$ base pairs in length and contains 13 exons. The Rattus norvegicus gene is slightly shorter at $\sim 92,000 \mathrm{bp}$, also with 13 exons. The Homo sapiens gene is $\sim 171,000$ bp with 16 exons. The arrangement and spacing of the $123^{\prime}$-most exons are similar in these three species; the increased length of the human gene appears to reflect extensions of the introns upstream of the fourth rat/mouse exon. Whereas the Drosophila counterpart is only $14,785 \mathrm{bp}$, it has 14 exons and 3 domains that are highly conserved within the vertebrate genes noted above; these are WW, myosin tail homology 4 (MyTH4), and GAP domains described below.

Through in silico and Northern blot analyses, as well as sequencing of full-length cDNAs in human, rat, and mouse, it has been clearly demonstrated that the Arhgap39/Porf-2 gene can give rise to multiple RNA transcripts (Nowak, 1990, 1997; Rietveld et al., 2014). Although it was briefly reported that there was a second related gene in the mouse (Lundström et al., 2004), it was subsequently shown to represent an alternative splice form of Arhgap39/Porf-2 mRNA. However, there is evidence that two of the major transcripts give rise to slightly 


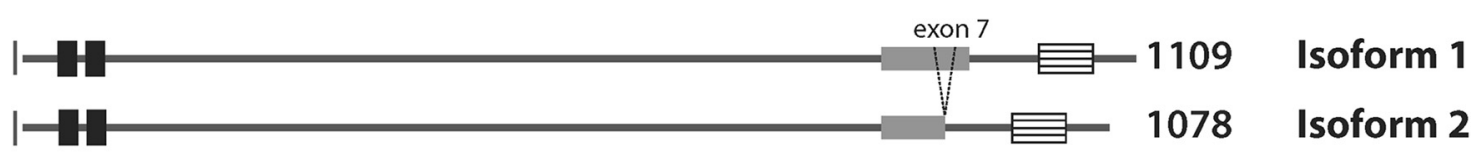

ww domains myTH4 domain E RhoGAP domain

Figure 2. Sequences of two isoforms of Arhgap39/Porf-2 protein in mouse. The protein sequence numbers correspond to those in the NCBI database. Adapted from https://www.ncbi.nlm.nih.gov/gene/223666 (mouse). The functional domains include two WW, and one each of MyTH4 and GAP. Protein isoform 2 differs from isoform 1 in the deletion of 31 amino acids, encoded by exon 7, from the MyTH4 domain.

different proteins, owing to alternative splicing of the inframe exon 7 (Fig. 2). The mouse protein isoforms 1 and 2 differ by elimination of exon 7 in isoform 2, which results in a 31-amino-acid deletion in the MyTH4 domain. Human isoforms 1 and 2 are similar to mouse isoform 2 and the single verified rat isoform in that they all encode a protein that lacks exon 7. Human isoforms 1 and 2 differ in their $5^{\prime}$ untranslated regions. In addition to the verified transcripts, there are a number of predicted transcripts. To a large extent, the resulting protein or other products of these transcripts have not been characterized. Alternative splicing occurs in $41 \%$ of mouse transcriptome and, in transcripts which contain a coding sequence, $79 \%$ of splice variations alter the protein products, and potentially, their subcellular localization and function (Okazaki et al., 2002). It remains to be seen whether there are different forms of Arhgap39/Porf-2 protein in different subcellular compartments or with alternative posttranslational modifications that allow for it to have several separate functions.

\section{Protein domains and modifications}

The RhoGAP family members are notable for having multiple functional domains in addition to the GAP domain, including many that have been implicated in protein-protein interactions. This organization may facilitate interactions with more than one signaling pathway (Moon and Zheng, 2003; Tcherkezian and Lamarche-Vane, 2007). In the mouse, as well as in Drosophila, Arhgap39/Porf-2 protein has been shown to have three potentially functional domain regions, as shown in Fig. 2.

\section{Two WW domains}

The first hypothesized functional region is represented by a pair of WW domains at the $\mathrm{N}$ terminus of the predicted Drosophila protein (Lundström et al., 2004) and mouse isoform 1 (Lim et al., 2014). WW domains are $\sim 35-45$ amino acids in length and are characterized by the presence of hydrophobic amino acids with cyclic side chains, including tryptophan, tyrosine, phenylalanine, and proline, but do not usually otherwise exhibit significant homology between different genes. However, the two WW domains of human Arhgap39/Porf-2 exhibit $84 \%$ and $77 \%$ sequence similarity, respectively, with the related drosophila Arhgap93B (Lundström et al., 2004). WW domains recognize and interact with proline-rich segments of other proteins to facilitate protein-protein interactions (Otte et al., 2003).

\section{MyTH4 domain}

The second region is a MyTH4 domain, an $\sim 150$ amino-acid module. MyTH4 domains have been identified as a conserved sequence in the tail domains of several different unconventional myosins and a plant kinesin-like microtubule protein. There is a $44 \%$ protein sequence similarity between the $H$. sapiens Arhgap39/Porf-2 and Drosophila Arhgap93B MyTH4 domains (Lundström et al., 2004). Although the function of MyTH4 domains is not yet fully understood, there is evidence that the MyTH4 domain of Myosin-X (Myo10) binds to microtubules (Kerber and Cheney, 2011). The MyTH4 domain has also been found in several nonmotor proteins. Interestingly, the results of Huang et al. (2002) suggest a possible role for one of these (MAX-1) in netrin-induced axon repulsion in Caenorhabditis elegans by modulating the UNC-5 receptor signaling pathway. MAX-1 homologues are also found in Drosophila, mouse, and human (Kikuno et al., 2000; Huang et al., 2002). An emerging theme is that many, and perhaps most, guidance cues are bifunctional. Arhgap39/ Porf-2 and MAX-1 are both MyTH4 domain-containing proteins that display this attraction-repulsion dichotomy.

\section{RhoGAP domain}

The third functional region is a RhoGAP domain close to the $\mathrm{C}$ terminus. RhoGAP domains are $\sim 140$ amino acids, sharing 20\%-40\% amino acid identity (Lamarche and Hall, 1994). The actual GTPases with which they interact cannot be predicted by the sequence but must be experimentally determined. The human Arhgap39/Porf-2 GAP domain shares $86.5 \%$ homology with the rat, $88.8 \%$ with the mouse (personal calculation), and 61\% with Drosophila (Lundström, Gallio, 2004). The rat also has transcripts that include the RhoGAP domain; however, it also has at least two variants, $\mathrm{X} 4$ and $\mathrm{X} 5$, that lack this domain. Instead, each contains a distinct C-terminal sequence.

\section{Additional motifs and modifications}

In addition to the WW, MyTH4, and GAP domains, the predicted protein isoforms 1 and 2 have 19 potential motif sites, including 8 serine/threonine phosphorylation sites, 2 $\mathrm{SH} 2$, and a single SH3 motif (Obenauer et al., 2003). Serine or tyrosine phosphorylation of regulatory proteins including GAPs is one mechanism by which activation and subcellular location can be controlled. One example is CdGAP, a RhoGAP whose activity is regulated through phosphorylation by ERK (Tcherkezian et al., 2005). Another example is the phosphorylation of the RacGAP 
Table 2. Tissue and cell type distribution of Arhgap39/Porf-2 expression in human, mouse, rat, and fruit fly

\begin{tabular}{|c|c|c|}
\hline Type of tissue or cell & Location (species) & Method of detection \\
\hline \multirow[t]{6}{*}{ Brain } & Hippocampus (R, M, H) & N, NPA, RNAi, IHC \\
\hline & Hypothalamus (R) & $\mathrm{N}, \mathrm{NPA}, \mathrm{ISH}$ \\
\hline & Cerebral cortex $(\mathrm{R}, \mathrm{M})$ & N, NPA, IHC; RNA Seq (Yue et al., 2014) \\
\hline & Cerebellum (R, M) & N, RNA Seq (Yue et al., 2014) \\
\hline & Amygdala $(\mathrm{R})$ & ISH \\
\hline & Ventral neuropil (D) & ISH (Lundström et al., 2004) \\
\hline Peripheral nervous system & Tracheal ganglia (D) & RNAi (Lundström et al., 2004) \\
\hline \multirow[t]{9}{*}{ Endocrine organs } & Testes $(\mathrm{R}, \mathrm{H}, \mathrm{M})$ & $\mathrm{N}, \mathrm{ISH}, \mathrm{EST}$ \\
\hline & Anterior pituitary $(\mathrm{R})$ & $\mathrm{N}$ \\
\hline & Adrenal $(\mathrm{H}, \mathrm{M}, \mathrm{R})$ & N, RNA Seq (Yu et al., 2014; Yue et al., 2014) \\
\hline & Placenta $(H, R, M)$ & N, EST (Ko et al., 2000); RNA Seq (Yu et al., 2014; Yue et al., 2014) \\
\hline & Ovary $(\mathrm{M}, \mathrm{H})$ & RNA Seq (Yue et al., 2014; Fagerberg et al., 2014) \\
\hline & Adipose tissue $(\mathrm{M}, \mathrm{H})$ & RNA Seq (Yue et al., 2014; Fagerberg et al., 2014) \\
\hline & Mammary gland (M) & RNA Seq (Yue et al., 2014) \\
\hline & Thyroid $(\mathrm{H})$ & RNA Seq (Fagerberg et al., 2014) \\
\hline & Pancreas $(\mathrm{H})$ & RNA Seq (Fagerberg et al., 2014) \\
\hline \multirow[t]{12}{*}{ Other organs } & Prostate $(\mathrm{H}, \mathrm{R})$ & N, RNA Seq \\
\hline & Liver $(\mathrm{R}, \mathrm{H}, \mathrm{M})$ & N, PCR, WB; RNA Seq (Yue et al., 2014) \\
\hline & Skin $(M, H)$ & EST (Miki et al., 2001); RNA Seq (Fagerberg et al., 2014) \\
\hline & Uterus $(\mathrm{R}, \mathrm{H})$ & RNA Seq (Yu et al., 2014; Fagerberg et al., 2014) \\
\hline & Lung $(\mathrm{R}, \mathrm{H})$ & RNA Seq (Yu et al., 2014; Fagerberg et al., 2014) \\
\hline & Spleen $(R, H)$ & RNA Seq (Yu et al., 2014); RNA Seq (Fagerberg et al., 2014) \\
\hline & Heart $(R, M)$ & RNA Seq (Yu et al., 2014; Yue et al., 2014) \\
\hline & Thymus (R, M) & RNA Seq (Yu et al., 2014; Yue et al., 2014) \\
\hline & Skeletal Muscle (R, M) & RNA Seq (Yu et al., 2014; Yue et al., 2014) \\
\hline & $\mathrm{Gl}$ tract $(\mathrm{M}, \mathrm{H})$ & RNA Seq (Yue et al., 2014; Fagerberg et al., 2014) \\
\hline & Bladder (M) & RNA Seq (Yue et al., 2014) \\
\hline & Kidney $(\mathrm{R}, \mathrm{H})$ & PCR; RNA Seq (Fagerberg et al., 2014) \\
\hline \multirow[t]{7}{*}{ Cells } & FRTL-5 (R thyroid-like) & WB, PCR \\
\hline & Pancreatic beta cells $(\mathrm{H})$ & PCR (Wang, 2011) \\
\hline & cos7 cells (nhP kidney) & PAGE \\
\hline & C17.2 (M cerebellar stem) & PCR, WB \\
\hline & GT-1 (M hypothalamic neuron) & WB \\
\hline & Vascular endothelial $(\mathrm{H})$ & IP (Kaur et al., 2008) \\
\hline & Melanocytes $(\mathrm{H})$ & ASSET (Watahiki et al., 2004) \\
\hline
\end{tabular}

D, Drosophila; H, human; M, mouse; nhP, nonhuman primate; R, rat; ASSET, alternative splicing sequence enriched tag; ISH, in situ hybridization; IP, immunoprecipitation; IHC, immunohistochemistry; N, Northern blot; NPA, nuclease protection assay; WB, Western blot. Unless otherwise noted, determinations were made in the authors lab.

protein, FilGAP, at Ser-402 (Morishita et al., 2015). Phosphorylation increases its RacGAP activity in vivo and promotes diffuse distribution in the cytoplasm, which stimulates cell spreading on fibronectin. The total number and active sites of phosphorylation in the Arhgap39/ Porf-2 protein have not been determined. One of the predicted phosphorylation sites in Arhgap39/Porf-2 at serine 169, within a casein kinase I motif, was confirmed by a screen of mouse synaptosomal proteins isolated from 2-5-month cortex (Munton et al., 2007). In addition, phospho-serine 589 was identified in a large screening of the developing mouse brain (E16.5) for phosphorylated peptides by Ballif et al. (2004); interestingly, this was not one of the phosphorylation sites previously predicted.

$\mathrm{SH} 2$ and $\mathrm{SH} 3$ are homology domains found in a family of oncogenic nonreceptor tyrosine kinases. An SH2 domain, which was first identified in the oncoproteins Src and Fujiyami poultry sarcoma, is $\sim 100$ amino acid residues long. It functions as a regulatory module of intracellular signaling cascades by interacting with high affinity to phosphotyrosine-containing target peptides in a sequencespecific and strictly phosphorylation-dependent manner.
SH3 domains are small protein domains of $\sim 60$ amino acid residues. SH3 domains are found in proteins of signaling pathways regulating the cytoskeleton, the Ras protein, the Src kinase, and many others. SH3 domains interact with other proteins and mediate assembly of specific protein complexes, typically via binding to proline-rich peptides in their respective binding partner.

The presence of these motifs that accelerate protein localization and interactions in Arhgap39/Porf-2 are consistent with its role as a RhoGAP that is involved in several complex signaling pathways.

\section{Tissue distribution of Arhgap39/PORF-2 RNAs and proteins (Table 2)}

The first partial Arhgap39 (Porf-2) sequence was reported in a cDNA library constructed with RNA isolated from adult rat hypothalamus (Nowak, 1990). This group detected multiple poly A-enriched RNA transcripts expressed widely in the adult rat, including cerebral cortex, hippocampus, hypothalamus, cerebellum, amygdala, anterior pituitary, adrenal, testis, liver, and kidney (Nowak, 1990, 1997, 2014). ESTs and alternative splicing se- 
Table 3. Functions and mediators of Arhgap39/Porf-2

\section{Functions}

1. Mediates axonal guidance and midline repulsion in developing Drosophila.

2. Regulates filopodia formation and directional migration of human vascular endothelial cells.

3. Delays cell cycle and decreases proliferation of mouse neural stem cell line, C17.2.

4. Promotes apoptosis in C17.2 cells.

5. Regulates dendritic spine morphology in embryonic rat hippocampal neurons.

6. Decreases neurogenesis in mouse hippocampus.

7. Plays a role in learning and memory.
Mediators of action

1. Robo, RacGTP, Slit (Lundström et al., 2004; Hu et al., 2005)

2. Robo1 and Robo4, Cdc42, IRSp53, MENA, actin nucleation (Kaur et al., 2008)

3. p21, decreased progression from $\mathrm{G} 1$ to $\mathrm{S}$ (Ma and Nowak, 2011)

4. BAX, p53 (Ma and Nowak, 2011)

5. CNK2, Rac1 (Lim et al., 2014)

6. Rac1, $\beta$-catenin (Huang et al., 2016)

7. Hippocampal synaptic signaling (Lee et al., 2017) quence enriched tags (ASSETs; Watahiki et al., 2004) were also found in E7.5 mouse embryo placental growth cone (Ko et al., 1998) and E17.5 mouse skin and testes (Miki et al., 2001). In 2001, human KIAA1688 cDNA was sequenced, and human tissue distribution of Arhgap39/ Porf-2 RNA was quantified by PCR (Kikuno et al., 2004). Although RNA levels were highest in brain and spinal cord, it was also found in testis, kidney, liver, pancreas, lung, and other tissues at lower levels.

RNA transcripts have also been detected in human hypothalamus, adrenal, prostate, and placenta (Nowak, 2014) and in several cultured cell types, including human melanocytes (Watahiki et al., 2004), human vascular endothelial cells (Kaur et al., 2008), mouse cerebellar stem cells (C17.2; Ma and Nowak, 2011), Fisher rat thyroid-like (FRTL-5) cells, mouse hypothalamic neurons (GT-1; Nowak, 2014), and human pancreatic beta cells (Wang J., 2012, personal communication). Recently, several extensive studies of gene expression in human (Fagerberg et al., 2014), mouse (Yue et al., 2014), and rat (Yu et al., 2014) have expanded the molecular distribution of Arhgap39/Porf-2 RNA to include intestine, spleen, heart, thymus, uterus, lung, stomach, ovary, urinary bladder, mammary gland, prostate, salivary gland, thyroid gland, and adipose tissue.

Ballif et al. (2004) identified an Arhgap39/Porf-2 phosphopeptide in a large proteomic analysis of E16.5 mouse brain. Diez-Roux et al. (2011) found moderate protein expression of Arhgap39/Porf-2 (D15Wsu169e) in E14.5 mouse embryo brain and spinal cord and peripheral nervous system, and low expression in multiple other peripheral locations, including renal, hematopoietic, gastrointestinal, and smooth and striated muscle. Arhgap39/ Porf-2 protein expression was also reported in mouse cerebellar stem cells (Ma and Nowak, 2011). Recently, several Arhgap39/Porf-2 proteins were detected in human male liver (unpublished observations, Liu, Zhang, Guo, and Nowak).

In the brain, Arhgap39/Porf-2 RNA was first localized to neurons (Nowak et al., 1999) in 60-d-old female rat hypothalamus by in situ hybridization analysis. It was later detected as a phosphoprotein by liquid chromatographytandem mass spectrometry in synaptic terminals isolated from 2-5-month C57BI/6 mouse cortex (Munton et al., 2007). Arhgap39/Porf-2 is also detected in neurospheres derived from mouse hippocampus (Huang et al., 2016).

\section{Functional roles and downstream effectors (Table 3)}

Arhgap39/Porf-2 has been shown to function through regulation of two Rho GTPases, Rac1 and Cdc42. Several investigators have shown that Arhgap39/Porf-2 is a regulator of Rho GTPases and as such plays a role in endothelial cell migration (Kaur et al., 2008), ganglion and axon tracking (Lundström et al., 2004; Hu et al., 2005), neural stem cell fate (Ma and Nowak, 2011; Huang et al., 2016), and dendritic spine formation (Lim et al., 2014; Lee et al., 2017). These studies further link Arhgap39/Porf-2 to angiogenesis, tracheal innervation, and CNS development.

\section{Axon directional migration}

Lundström et al. (2004) were the first to show a functional role for Arhgap93B, the Drosophila ortholog of Arhgap39/Porf-2. They demonstrated that the WW domains of Vilse, as they termed it, bind to the CC2 domain of the Slit receptor, Roundabout (Robo), and inactivate RacGTP to mediate Slit-directed midline repulsion of CNS axons in tracheal cells. They further demonstrated that both Drosophila Arhgap93B and human Arhgap39/Porf-2 GAP domains effectively stimulated GTP hydrolysis of Rac1. Soon thereafter, Hu et al. (2005) identified Vilse, which they called CrossGAP, as a regulator of midline axonal repulsive guidance in Drosophila. They confirmed the direct interaction between Vilse and Robo and the inactivation of Rac1 by Vilse. Interestingly, either too little or too much Vilse resulted in defective Robo-mediated, Slit-directed axon repulsion at the midline.

\section{Endothelial cell migration}

In human vascular endothelial cells, Arhgap39/Porf-2/ Vilse is sequestered by Robo1 and Robo4, resulting in an increase in activated Cdc42. Cdc42-GTP then activates insulin receptor protein 53 (IRSp53) by binding to its CRIB domain. This exposes an $\mathrm{SH} 3$ domain that binds to Mena, an IRSp53 effector and mediates actin nucleation, resulting in filopodia formation and endothelial cell directional migration (Kaur et al., 2008).

\section{Neural stem cell fate}

In 2011, the roles of Arhgap39/Porf-2 in the mouse neural stem cell (NSC) line, C17.2, were discovered, including its negative effects on cell cycle and proliferation and potentiating effects on apoptosis. The key cell sig- 
naling components involved in mediating these effects were identified (Ma and Nowak, 2011). These include increased levels of p21 leading to cell cycle arrest and decreased cell proliferation, and enhanced drug-induced apoptosis through both p53-dependent and -independent pathways by upregulating $\mathrm{Bcl}-2$ associated $\mathrm{X}$ protein (BAX). These findings are consistent with those of others who have shown that BAX and p53 are regulators of programmed cell death in mouse cerebellum (Geng et al., 2010) as well as with the finding that upregulation of BAX and p53 can suppress the growth of tumors, including gliomas (Zhen et al., 2017).

This work also demonstrated that Arhgap39/Porf-2 had no effect on NSC differentiation induced by serum starvation (Ma and Nowak, 2011). Although this study did not identify the GTPase substrate involved, Ras, Rho, and Cdc42 have all been shown to regulate cell cycle entry and cell proliferation (Olson et al., 1995; Olson et al., 1998; Welsh et al., 2001) and to determine the fate of NSCs by influencing the balance of stem cell maintenance with proliferation and apoptosis (Joseph and Hermanson, 2010). Other RhoGAPs including DLC2 (Ching et al., 2003) and tGAP1 (Modarressi et al., 2004) have been shown to decrease cell proliferation by slowing down the cell cycle. tGAP1 also induces apoptosis when overexpressed in somatic cells.

Huang et al. (2016) showed that the effects of Arhgap39/Porf-2 on cell proliferation of NSCs were mediated through its GAP domain. They extended previous in vitro findings in C17 cells that Arhgap39/Porf-2 is antiproliferative (Ma and Nowak 2011) and demonstrated that Arhgap39/Porf-2 decreases proliferation in neurospheres from newborn mouse hippocampus as well as in hippocampal sections from 6-week-old mice (Huang et al., 2016). Transfection with a full-length Arhgap39/Porf-2 construct, but not one lacking the GAP domain, resulted in decreased levels of intranuclear $\beta$-catenin. The authors postulated that the observed effects on cell proliferation are mediated through the GAP domain, causing decreased translocation of $\beta$-catenin into the nucleus.

\section{Dendritic spine morphology}

Lim et al. (2014) demonstrated that Arhgap39/Porf-2 is required for normal dendritic spine formation in the rat dentate gyrus, a portion of the hippocampal formation, and in mouse neuroblastoma $\times$ rat glioma hybrid cells. Interaction of a proline motif in the neuron scaffold protein connector enhancer of kinase suppressor of ras2 (CNK2) with the WW domain of Vilse regulates Arhgap39/Porf-2 localization. This critical interaction maintains the RacGDP/ GTP balance required for dendritic spine formation. It is of note that CNK2 has been implicated in X-linked cognitive impairment in a human subject (Houge et al., 2012). Additionally, constitutive lack of the RhoGAP, oligophrenin 1, in mice results in decreased density and increased length of dendritic spines in the amygdala (Khelfaoui et al., 2014) and failure of hippocampal CA1 dendritic spines to mature during development (Khelfaoui et al., 2007). These mice also display deficits in learning and memory as measured with Y-maze, O-maze, Morris water maze, and conditioned fear extinction, as well as altered hippocampal LTP. Deficits in mice of additional Rho GTPase regulators, including SRGAP3, BCR and ABR, ARG, ABL, Integrin $3 \alpha$, KALRN, and ARGEF6, have also been associated with cognitive and anxiety-related behavioral alterations, such as decreases in novel object recognition and Y-maze alternation and social interactions, altered synaptic plasticity, and abnormal dendritic spine morphology (De Filippis et al., 2014). Finally, exome sequencing of individuals from a family with late-onset Parkinson's disease identified a mutation (p.Arg667GIn) in Arhgap39/ Porf-2 as a rare variant possibly associated with the disease (Schulte et al., 2014), indicating that dysregulation of this gene may also play a role in neurodegeneration.

\section{Learning and memory}

In 2014, Arhgap39/Porf-2 was among the genes identified to be associated with cognitive performance in humans (Rietveld et al., 2014). This may reflect variation in expression of mRNA variants 1 and 2, an interesting observation, since they both encode the same protein isoform, but differ in the 5' UTR. Quite recently, Lee et al. (2017) described the effects in hippocampus of a widespread Arhgap39/Porf-2 knockout in mouse forebrain under the direction of the CamKII promoter. These mice show behavioral deficits in learning and memory as measured by Morris water maze and Y-maze performance. They also exhibit abnormal hippocampal signaling and dendritic spine morphology. Not surprisingly, given its high level of expression in placental growth cone and developing nervous system, a global constitutive knockout resulted in embryonic lethality, with incomplete embryo development.

Taken together, these findings indicate that Arhgap39/ Porf-2 is an integral part of the signaling machinery that regulates hippocampal structure and function and more broadly neuronal function, through its effects on neuronal cell proliferation and apoptosis, its regulation of axonal migration, and its role in dendritic spine morphology, synaptic plasticity, and cognitive performance.

\section{Oncogenesis}

More recently, several bioinformatics analyses have uncovered associations of Arhgap39/Porf-2 mutations or variations in copy number or expression level with several types of cancer (https://cancer.sanger.ac.uk/cosmic/ gene/analysis?ln=ARHGAP39, http://useast.ensembl.org/ Homo_sapiens/Gene/Variation_Gene/Table?db=core; $g=E N S G 00000147799 ; r=8: 144529179-144605816)$. These include tumors of the CNS, skin, prostate, and gastrointestinal tract; one conserved variant has been shown to correlate with prostate tumors and sarcomas in a family lineage (Jones, 2017). Given its roles in apoptosis and proliferation and interactions with p53 and BAX, a mutation that decreased expression of Arhgap39/Porf-2 could result in increased cell proliferation, leading to tumorigenesis. 
Table 4. Variables modifying expression and upstream regulators of Arhgap39/Porf-2

Developmental stage (rat brain)

Age (rat brain and testes)

Sex (rat brain)

Brain region (rat)

Gonadal hormones, including estradiol and progesterone (rat brain)

Pituitary factors (rat brain and testes)

Epigenetic mechanisms such as miRNAs

Insulin and IGF-1 (FRTL-5 cells)

Type 2 diabetes (Zucker rat kidney)

Obesity (human liver)

\section{Variables modifying expression and upstream regulators of Arhgap39/PORF-2 (Table 4)}

Whereas it is important to know the downstream effects of Arhgap39/Porf-2 action, it is also critical to understand the physiologic factors that regulate Arhgap39/Porf-2 expression. It has been known for some time that Arhgap39/ Porf-2 mRNA in the rat brain is localized mainly to neurons (Nowak et al., 1999) and that in the rat, age, sex differences, brain region, gonadal steroids, and developmental stage regulate/influence the expression of Arhgap39/ Porf-2 mRNAs in hippocampus, hypothalamus, and cerebral cortex (Hu and Nowak, 1994, 1995; Nowak, 1997; Nowak and Gore, 1999; Nowak et al., 1999).

\section{Developmental and age-related changes in CNS expression of Arhgap39/Porf-2}

As measured by nuclease protection assays of cytoplasmic RNA, Arhgap39/Porf-2 RNA averages $40 \mu \mathrm{g} / \mathrm{g}$ total RNA from $15 \mathrm{~d}$ to 2 months of age in the male rat hippocampus. The levels increase more than 2-fold at 6 and 12 months, then decline with age. Why Arhgap39/ Porf-2 is highest in the male rat hippocampus at middle age remains an unsolved question. Prenatal Arhgap39/ Porf-2 RNA levels in the POA are high at E18-E19, then fall gradually until P15. This is followed by a plateau through 2 months of age when postnatal levels are highest $(19.9 \mu \mathrm{g} / \mathrm{g})$ followed by a progressive decrease with age (Hu and Nowak, 1994). Postnatal age-related changes in expression have also been identified in the $\mathrm{MBH}$ and cerebral cortex (Hu and Nowak, 1995), where Arhgap39/ Porf-2 RNA is severalfold higher in both male and female rats at $15 \mathrm{~d}$ compared to 30 and $60 \mathrm{~d}$, followed by a long plateau through 24 months of age. Arhgap39/Porf-2 RNA in the $\mathrm{MBH}$ also declines rapidly by 2-fold from E18-E19 to P15 in both sexes (Nowak and Gore, 1999). Its regionally distinctive, developmentally modified neuronal expression suggested early on that Arhgap39/Porf-2 has a critical role in prenatal and postnatal CNS development and function.

\section{Sex differences in the developing CNS}

There are also sex differences in Arhgap39/Porf-2 cytoplasmic RNA levels during development in the rat, being higher in male than in female hippocampus and $\mathrm{MBH}$ at P15 (Hu and Nowak, 1995). In the POA, late embryonic levels are higher in males at E18-E19, then decline rap- idly, resulting in lower levels in males at P0 and P15 (Nowak and Gore, 1999). Thus there is a sex difference in timing for peak levels of Arhgap39/Porf-2 in the developing rat fetal POA, a brain region that is critical for normal feedback regulation of gonadotropin-releasing and -inhibiting hormones and reproductive function more generally.

\section{Gonadal hormones}

In the adult rat, Arhgap39/Porf-2 expression is responsive to extrinsic variations in circulating gonadal hormones in both females and males. In females ovariectomized at 44 days, treatment with E2 alone results in an increased level of Arhgap39/Porf-2 RNA in the POA and hippocampus compared with placebo-treated controls (Nowak et al., 1999). Replacement of only P4 upregulates Arhgap39/Porf-2 in POA and cerebral cortex. Treatment with E2 plus P4 also increases Arhgap39/Porf-2 in the hippocampus, but this combination decreases the RNA in POA and cortex. No changes are observed in the $\mathrm{MBH}$. Thus the response of the female rat brain to gonadal steroids is highly region dependent. Based on Northern blot analysis of Arhgap39/Porf-2 mRNA in male rats subjected to hypophysectomy or castration, both pituitary and testicular factors directly or indirectly affect alternative splicing of Arhgap39/Porf-2 mRNA transcripts in the POA, MBH, and cerebral cortex (Nowak, 1997). At the present time, it is not known how this specifically impacts sex-related gene function or how Arhgap39/Porf-2 mediates the effects of reproductive axis hormones in the brain.

\section{Pituitary factors}

Expression of Arhgap39/Porf-2 RNA in rat testes is predominantly localized to spermatogonia and primary spermatocytes and is regulated by age and by pituitary gonadotrophic hormones (Nowak et al., 1997). Arhgap39/ Porf-2 testicular expression declines with age in the rat (Nowak et al., 1997; Yu et al., 2014). At $60 \mathrm{~d}$ of age, Arhgap39/Porf-2 RNA has declined to $40 \%$ of the level at $15 \mathrm{~d}$; there is a further $50 \%$ decline between $60 \mathrm{~d}$ and $6-12$ months. By 24 months, the level is $8 \%-28 \%$ of that at $15 \mathrm{~d}$. Hypophysectomy of young adult male rats results in a significant increase in testicular Arhgap39/Porf-2 to levels normally seen at $15 \mathrm{~d}$. Although the developmental pattern of expression, in addition to the germ cell location and regulation by hormones of reproduction, suggests a function for Arhgap39/Porf-2 proteins in mammalian testes, that specific function is currently unknown. Another RhoGAP, tGAP1, which is mainly found in testes, has been shown to be expressed later, in round spermatids, where it slows down the cell cycle and may induce apoptosis (Modarressi et al., 2004).

\section{Epigenetic mechanisms}

Recently, epigenetic mechanisms have been implicated in the regulation of Arhgap39/Porf-2 expression (https:// ccb-web.cs.uni-saarland.de/mirtargetlink/network.php? type $=$ Target_Gene\&qval=ARHGAP39). miRTargetLink currently lists 23 miRNAs with weaker experimental evidence that may target Arhgap39/Porf-2. 


\section{Metabolism, insulin, and IGF-1}

More recently, it was discovered that Arhgap39/Porf-2 expression is also modified by two important regulators of metabolism and growth, insulin and IGF-1 (Wang, 2011). Both insulin and IGF-1 decrease Arhgap39/Porf-2 expression in FRTL-5 cells in a dose- and time-dependent manner. That this downregulation is signaled through the PI-3-kinase/AKT and Raf kinase/MEK pathways was shown by use of specific chemical inhibitors, including wortmannin and Ly29402 for PI-3-K and Akt inhibitor-4, Raf kinase inhibitor, and high-dose wortmannin and PD98059 for MEK/Erk phosphorylation. Additionally, knockdown of IGF-1 receptor (IGF-1R) and possibly insulin receptor results in a partial reversal of the downregulation. An additional study of interest (Bentov et al., 2014) showed an association of IGF-1R deficiency in aged dermal fibroblasts with decreased Erk phosphorylation and decreased cell proliferation. Although Arhgap39/Porf-2 is expressed in skin and is a potential mediator of this effect, neither it nor other potential downstream regulators were measured in this study.

It makes physiologic sense that stimulators of growth and metabolism would act counter to Arhgap39/Porf-2, a regulator that promotes apoptosis and inhibits cell proliferation. Recent findings have shown that neurogenesis is impaired and apoptosis increases in hippocampi of subjects with diabetes (Ho et al., 2013). A logical question that follows is, what happens to endogenous levels of Arhgap39/Porf-2 when insulin or IGF-1 is deficient as in type 1 diabetes or growth hormone deficiency, either congenital (Laron syndrome) or age-related (Gong et al., 2014), or if the response to insulin or IGF-1 is blocked, as seen in obesity with insulin resistance, type 2 diabetes, or aging (Bentov et al., 2014)?

\section{Insulin resistance and obesity}

Two recent findings suggest a link between insulin resistance and Arhgap39/Porf-2. In a Zucker rat model of obesity-related diabetes, treatment with an antioxidantfortified diet resulted in partial preservation of glomerular filtration rate in 20-wk-old diabetic females (Slyvka et al., 2009). This group also found decreased expression of Arhgap39/Porf-2 RNA in the kidney compared to diabetic females on a control diet. Obese humans and rodents also have been shown to have decreased hepatic expression of Arhgap39/Porf-2 and carcinoembryonic antigen related cell adhesion molecule 1 (Heinrich et al., 2017). Decreased carcinoembryonic antigen related cell adhesion molecule 1 leads to a decrease in insulin clearance, exacerbating hyperinsulinemia. Thus the decrease in Arhgap39/Porf-2 could be a result of increased suppression by insulin in the prediabetic state, although later, as insulin resistance with hyperinsulinemia advances to frank diabetes, Arhgap39/Porf-2 levels can be anticipated to rise. Both insulin and IGF-1 deficiencies have been linked to neurodegenerative (Biessels et al., 2014; Ekblad et al., 2017) and cardiovascular (Higashi et al., 2013) disease. This, in conjunction with the above findings, raises the question of whether increased Arhgap39/Porf-2 expres-
Table 5. Potential physiologic roles of Arhgap39/Porf-2

Sexual dimorphism of hypothalamus

Axon guidance and directional migration

Regulation of early sperm development

Endothelial cell migration

Regulation of cell cycle in neural stem cells

Development of normal dendritic spine morphology

Cognitive performance

Development and function of extraembryonic structures

Table 6. Potential pathophysiological roles of Arhgap39/ Porf-2

Congenital cognitive insufficiency

Age-related cognitive

decline/neurodegeneration

Diabetic nephropathy

Diabetes-related cognitive dysfunction

Obesity-related hepatic dysfunction

Cognitive decline related to IGF-1 deficiency

Oncogenesis

sion factors into the pathophysiology of diabetic complications more generally.

\section{Potential physiologic and pathophysiological roles of Arhgap39/Porf-2}

Tables 5 and 6 summarize the potential physiologic and pathophysiological roles of Arhgap39/Porf-2, based on the findings to date. Its wide phylogenetic and tissue distribution, its complex physiologic regulation, and its pivotal role in basic cell functions support the expectation that there is much more to discover about this particular RhoGAP.

\section{Summary}

Arhgap39/Porf-2 (Vilse, CrossGAP) is a Rho GTPase activating protein that interacts with Rac1 and Cdc42. As is the case with many RhoGAPs, it has multiple functions. Among these are inhibition of cell proliferation, promotion of apoptosis, regulation of axon guidance and endothelial cell migration, and development of normal dendritic spine morphology in the hippocampus, which may underlie support of normal learning and memory. Various physiologic and hormonal cues direct region-specific expression in the brain, suggesting that day-to-day expression is carefully monitored and maintained. Finally, the finding that deletion of Arhgap39/Porf-2 is fatal and the fact that this gene has been conserved through evolution for millennia highlight the crucial importance of this gene.

\section{References}

Ballif BA, Villén J, Beausoleil SA, Schwartz D, Gygi SP (2004) Phosphoproteomic analysis of the developing mouse brain. Mol Cell Proteomics 3:1093-1101. CrossRef Medline

Bentov I, Damodarasamy M, Plymate S, Reed MJ (2014) Decreased proliferative capacity of aged dermal fibroblasts in a three dimensional matrix is associated with reduced IGF1R expression and activation. Biogerontol 15:329-337. CrossRef

Biessels GJ, Strachan MW, Visseren FL, Kappelle LJ, Whitmer RA (2014) Dementia and cognitive decline in type 2 diabetes and prediabetic stages: towards targeted interventions. Lancet Diabetes Endocrinol 2:246-255. CrossRef Medline 
Bonaldo MF, Lennon G, Soares MB (1996) Normalization and subtraction: two approaches to facilitate gene discovery. Genome Res 6:791-806. Medline

Carninci P, Shibata $Y$, Hayatsu N, Sugahara $Y$, Shibata K, Itoh M, Konno H, Okazaki Y, Muramatsu M, Hayashizaki Y (2000) Normalization and subtraction of cap-trapper-selected cDNAs to prepare full-length cDNA libraries for rapid discovery of new genes. Genome Res 10:1617-1630. Medline

Ching YP, Wong CM, Chan SF, Leung TH, Ng DC, Jin DY, Ng IO (2003) Deleted in liver cancer (DLC) 2 encodes a RhoGAP protein with growth suppressor function and is underexpressed in hepatocellular carcinoma. J Biol Chem 278:10824-10830. CrossRef Medline

De Filippis B, Romano E, Laviola G (2014) Aberrant Rho GTPases signaling and cognitive dysfunction: in vivo evidence for a compelling molecular relationship. Neurosci Biobehav Rev 46: 285301. CrossRef

Diez-Roux G, Banfi S, Sultan M, Geffers L, Anand S, Rozado D, Magen A, Canidio E, Pagani M, Peluso I, Lin-Marq N, Koch M, Bilio M, Cantiello I, Verde R, et al. (2011) A high-resolution anatomical atlas of the transcriptome in the mouse embryo. PLoS Biol 9:e1000582. CrossRef Medline

Ekblad LL, Rinne JO, Puukka P, Laine H, Ahtiluoto S, Sulkava R, Vitanen M, Jula A (2017) Insulin resistance predicts cognitive decline: an 11-year follow-up of a nationally representative adult population sample. Diabetes Care 40:751-758. CrossRef

Fagerberg L, Halström BM, Oksvold P, Kampf C, Djureinovic D, Odeberg J, Habuka M, Tahmasebpoor S, Danielsson A, Edlund K, Asplund A, Sjöstedt E, Lundberg E, Szigyarto CA, Skogs M, et al. (2014) Analysis of the human tissue-specific expression by genome-wide integration of transcriptomics and antibody-based proteomics. Mol Cell Proteom 13:397-406. CrossRef

Geng Y, Walls KC, Ghosh AP, Akhtar RS, Klocke BJ, Roth KA (2010) Cytoplasmic p53 and activated Bax regulate p53-dependent, transcription-independent neural precursor cell apoptosis. J Histochem Cytochem 58:265-275. CrossRef Medline

Gerhard DS, Wagner L, Feingold EA, Shenmen CM, Grouse LH, Schuler G, Klein SL, Old S, Rasooly R, Good P, Guyer M, Peck AM, Derge JG, Lipman D, Collins FS, et al. (2004) The status, quality, and expansion of the NIH full-length cDNA project: the Mammalian Gene Collection (MGC). Genome Res 14:2121-2127. CrossRef Medline

Ghosh P, Rangamani P, Kufareva I (2017) The GAPs, GEFs, GDIs and now GEMs: new kids on the heterotrimeric $G$ protein signaling block. Cell Cycle 16:607-612. CrossRef Medline

Gong Z, Kennedy O, Sun H, Wu Y, Williams GA, Klein L, Cardoso L, Matheny RW, Jr, Hubbard GB, Ikeno Y, Farrar RP, Schaffler MB, Adamo ML, Muzumdar RH, Yakar S (2014) Reductions in serum IGF-1 during aging impair health span. Aging Cell 13:408-418. CrossRef Medline

Heinrich G, Muturi HT, Rezaei K, Al-Share QY, DeAngelis AM, Bowman TA, Ghadieh HE, Ghanem SS, Zhang D, Garofalo RS, Yin L, Najjar SM (2017) Reduced hepatic carcinoembryonic antigenrelated cell adhesion molecule 1 level in obesity. Front Endocrinol 8:54-58. CrossRef Medline

Hestand MS, Kalbfleisch TS, Coleman SJ, Zeng Z, Liu J, Orlando L, MacLeod JN (2015) Annotation of the protein coding regions of the equine genome. PloS One 10:e0124375. CrossRef Medline

Higashi Y, Sukhanov S, Anwar A, Shai SY, Delafontaine P (2013) Aging, atherosclerosis, and IGF-1. J Gerontol Series A, Biol Sci Med Sci 67:626-639. CrossRef Medline

Ho N, Sommers MS, Lucki I (2013) Effects of diabetes on hippocampal neurogenesis: links to cognition and depression. Neurosci Biobehav Rev 37:1346-1362. CrossRef Medline

Houge G, Rasmussen IH, Hovland R (2012) Loss-of-function CNKSR2 mutation is a likely cause of non-syndromic X-linked intellectual disability. Mol Syndromol 2:60-63. Medline Medline

Hu H, Li M, Labrador JP, McEwen J, Lai EC, Goodman CS, Bashaw GJ (2005) Cross GTPase-activating protein (CrossGAP)/Vilse links the Roundabout receptor to Rac to regulate midline repulsion. Proc Natl Acad Sci U S A 102:4613-4618. CrossRef Medline

Hu SB, Nowak FV (1994) Regional distinction in age-related changes of preoptic regulatory factor-1 and preoptic regulatory factor-2 mRNA expression in the rat brain. Mol Cell Neurosci 5:376-381. CrossRef Medline

Hu SB, Nowak FV (1995) Sex-specific changes in preoptic regulatory factor-1 and preoptic regulatory factor- 2 mRNA expression in the rat brain during development. Endocrine 3:421-424. CrossRef Medline

Huang GH, Yang XT, Chen K, Xing J, Guo L, Zhu L, Li HJ, Li XC, Zhang SY, Feng DF (2016) Porf-2 inhibits neural stem cell proliferation through Wnt/beta-catenin pathway by its GAP domain. Front Cell Neurosci 10:85-97. CrossRef Medline

Huang X, Cheng HJ, Tessier-Lavigne M, Jin Y (2002) MAX-1, a novel $\mathrm{PH} / \mathrm{MyTH}$ /FERM domain cytoplasmic protein implicated in netrin-mediated axon repulsion. Neuron 34:563-76. Medline

Jiang SY, Ramachandran S (2006) Comparative and evolutionary analysis of genes encoding small GTPases and their activating proteins in eukaryotic genomes. Physiol Genomics 24:235-251. CrossRef Medline

Jones, RM. (2017) Identification of novel risk variants for sarcoma and other cancers by whole exome sequencing in cancer cluster families. PhD Thesis, The University of Western Australia. Available at http://research-repository.uwa.edu.au/files/21715375/thesisdoctor_of_philosophy_jones_Rachel_Maree_2017.pdf.

Joseph B, Hermanson O (2010) Molecular control of brain size: regulators of neural stem cell life, death and beyond. Exp Cell Res 316:1415-1421. CrossRef Medline

Kaur S, Samant GV, Pramanik K, Loscombe PW, Pendrak ML, Roberts DD, Ramchandran R (2008) Silencing of directional migration in roundabout4 knockdown endothelial cells. BMC Cell Biol 9:61-72. CrossRef Medline

Kawai J, Shinagawa A, Shibata $K$, Yoshino $M$, Itoh $M$, Ishii $Y$, Arakawa T, Hara A, Fukunishi Y, Konno H, Adachi J, Fukuda S, Aizawa K, Izawa M, Nishi J, et al. (2001) Functional annotation of a full-length mouse cDNA collection. Nature 409:685-690. CrossRef Medline

Kerber ML, Cheney RE (2011) Myosin-X: a MyTH-FERM myosin at the tips of filopodia. J Cell Sci 124:3733-3741. CrossRef Medline

Khelfaoui M, Denis C, van Galen E, de Bock F, Schmitt A, Houbron C, Morice E, Giros B, Ramakers G, Fagni L, Chelly J, NostenBertrand M, Billuart P (2007) Loss of X-linked mental retardation gene oligophrenin1 in mice impairs spatial memory and leads to ventricular enlargement and dendritic spine immaturity. J Neurosci 27:9439-9450. CrossRef Medline

Khelfaoui M, Gambino F, Houbaert X, Ragazzon B, Müller C, Carta M, Lanore F, Srikumar BN, Gastrein P, Lepleux M, Zhang CL, Kneib M, Poulain B, Reibel-Foisset S, Vitale N, Chelly J, Billuart P, Lüthi A, Humeau Y (2014) Lack of the presynaptic RhoGAP protein oligophrenin1 leads to cognitive disabilities through dysregulation of the cAMP/PKA signalling pathway. Phil Trans R Soc B 369: 20130160. CrossRef Medline

Kikuno R, Nagase T, Nakayama M, Koga H, Okazaki N, Nakajima D, Ohara O (2004) HUGE: a database for human KIAA proteins, a 2004 update integrating HUGEppi and ROUGE. Nucleic Acids Res 32:D502-504. CrossRef Medline

Kikuno R, Nagase T, Waki M, Ohara O (2000) HUGE: a database for human large proteins identified in the Kasuza cDNA sequencing project. Nucl Acids Res 28:331-332. CrossRef

Ko MS, Kitchen JR, Wang X, Threat TA, Wang X, Hasegawa A, Sun T, Grahovae MJ, Kargul GJ, Lim MK, Cui Y, Sano Y, Tanaka T, Liang Y, Mason S, et al. (2000) Large-scale cDNA analysis reveals phased gene expression patterns during preimplantation mouse development. Development 127:1737-1749.

Ko MS, Threat TA, Wang X, Horton JH, Cui Y, Wang X, Pryor E, Paris J, Wells-Smith J, Kitchen JR, Rowe LB, Eppig J, Satoh T, Brant L, Fujiwara H, Yotsumoto S, Nakashima H (1998) Genome-wide mapping of unselected transcripts from extraembryonic tissue of 7.5-day mouse embryos reveals enrichment in the t-complex and 
under-representation on the $\mathrm{X}$ chromosome. Hum Mol Genet 7:1967-1978. Medline

Lamarche N, Hall A (1994) GAPs for rho-related GTPases. Trends Genet 10:436-40. Medline

Lee JY, Lee LJ, Fan CC, Chang HC, Shih HA, Min MY, Chang MS (2017) Important roles of Vilse in dendritic architecture and synaptic plasticity. Sci Rep 7:45646. CrossRef Medline

Lim J, Ritt DA, Zhou M, Morrison DK (2014) The CNK2 scaffold interacts with vilse and modulates Rac cycling during spine morphogenesis in hippocampal neurons. Curr Biol 24:786-792. CrossRef Medline

Lundström A, Gallio M, Englund C, Steneberg P, Hemphälä J, Aspenström P, Keleman K, Falileeva L, Dickson BJ, Samakovlis C (2004) Vilse, a conserved Rac/Cdc42 GAP mediating Robo repulsion in tracheal cells and axons. Genes Dev 18:2161-2171. CrossRef Medline

Ma S, Nowak FV (2011) The RhoGAP domain-containing protein, Porf-2, inhibits proliferation and enhances apoptosis in neural stem cells. Mol Cell Neurosci 46:573-582. CrossRef Medline

Miki R, Kadota K, Bono H, Mizuno Y, Tomaru Y, Carninci P, Itoh M, Shibata K, Kawai J, Konno H, Watanabe S, Sato K, Tokusumi Y, Kikuchi N, Ishii Y, et al. (2001) Delineating developmental and metabolic pathways in vivo by expression profiling using the RIKEN set of 18,816 full-length enriched mouse cDNA arrays. Proc Natl Acad Sci U S A 98:2199-2204. CrossRef Medline

Modarressi MH, Cheng M, Tarnasky HA, Lamarche-Vane N, de Rooij DG, Ruan Y, van der Hoorn FA (2004) A novel testicular RhoGAPdomain protein induces apoptosis. Biol Reprod 71:1980-1990. CrossRef Medline

Moon SY, Zheng Y (2003) Rho GTPase-activating proteins in cell regulation. Trends Cell Biol 13:13-22. Medline

Morishita Y, Tsutsumi K, Ohta Y (2015) Phosphorylation of serine 402 regulates RacGAP protein activity of FilGAP protein. J Biol Chem 290:26328-26338. CrossRef Medline

Mouse Genome Sequencing Consortium, Waterston $\mathrm{RH}$, et al. (2002) Initial sequencing and comparative analysis of the mouse genome. Nature 420:520-562. CrossRef Medline

Munton RP, Tweedie-Cullen R, Livingstone-Zatchej M, Weinandy F, Waidelich M, Longo D, Gehrig P, Potthast F, Rutishauser D, Gerrits B, Panse C, Schlapbach R, Mansuy IM (2007) Qualitative and quantitative analyses of protein phosphorylation in naive and stimulated mouse synaptosomal preparations. Mol Cell Proteomics 6:283-293. CrossRef Medline

Nowak FV (1990) Cloning of two hypothalamic cDNAs encoding tissue-specific transcripts in the preoptic area and testis. Mol Endocrinol 4:1205-1210. CrossRef Medline

Nowak FV (1997) Modulation of preoptic regulatory factor-2 (porf-2) mRNAs by castration and hypophysectomy. Endocrine 6:57-63. CrossRef Medline

Nowak FV (2014) Preoptic regulatory factor-2, a Rhogap domain protein that modifies cell cycle progression and apoptosis in the CNS. In: Stem Cells and Cancer Stem Cells, Vol 12 (Hayat MA, editor). New York: Springer Nature, pp. 219-230.

Nowak FV, Gore AC (1999) Perinatal developmental changes in expression of the neuropeptide genes preoptic regulatory factor-1 and factor-2, neuropeptide $\mathrm{Y}$ and $\mathrm{GnRH}$ in rat hypothalamus. J Neuroendocrinol 11:951-958. Medline

Nowak FV, Torres G, Golden J, Hu SB (1997) Expression of the preoptic regulatory factor-1 and -2 genes in rat testis. Developmental and hormonal regulation. Endocrine 6:65-72. CrossRef Medline

Nowak FV, Torres GE, Hu SB (1999) Differential gene expression response to gonadal hormones by preoptic regulatory factors-1 and -2 in the female rat brain. Neuroendocrinology 69:191-201. CrossRef Medline

Obenauer JC, Cantley LC, Yaffe MB (2003) Scansite 2.0: Proteomewide prediction of cell signaling interactions using short sequence motifs. Nucleic Acids Res 31:3635-3641. Medline

Okazaki N, Kikuno RF, Ohara R, Inamoto S, Koseki H, Hiraoka S, Saga Y, Seino S, Nishimura M, Kaisho T, Hoshino K, Kitamura H,
Nagase T, Ohara O, Koga $\mathrm{H}$ (2004) Prediction of the coding sequences of mouse homologues of KIAA gene: IV. The complete nucleotide sequences of 500 mouse KIAA-homologous cDNAs identified by screening of terminal sequences of cDNA clones randomly sampled from size-fractionated libraries. DNA Res 11: 205-218. CrossRef

Okazaki Y, Furuno M, Kasukawa T, Adachi J, Bono H, Kondo S, Nikaido I, Osato N, Saito R, Suzuki H, Yamanaka I, Kiyosawa H, Yagi K, Tomaru Y, Hasegawa Y, et al. (2002) Analysis of the mouse transcriptome based on functional annotation of 60,770 full-length cDNAs. Nature 420:563-573. CrossRef Medline

Olson MF, Ashworth A, Hall A (1995) An essential role for Rho, Rac, and Cdc42 GTPases in cell cycle progression through G1. Science 269:1270-1272. Medline

Olson MF, Paterson HF, Marshall CJ (1998) Signals from Ras and Rho GTPases interact to regulate expression of p21Waf1/Cip1. Nature 394:295-299. CrossRef Medline

Otte L, Wiedemann U, Schlegel B, Pires JR, Beyermann M, Schmieder P, Krause G, Volkmer-Engert R, Schneider-Mergener J, Oschkinat H (2003) WW domain sequence activity relationships identified using ligand recognition propensities of $42 \mathrm{WW}$ domains. Protein Sci 12:491-500. CrossRef Medline

Peck J, Douglas G, Wu CH, Burbelo PD (2002) Human RhoGAP domain-containing proteins: structure, function and evolutionary relationships. FEBS Lett 528:27-34. CrossRef

Rietveld CA, Esko T, Davies G, Pers TH, Turley P, Benyamin B, Chabris CF, Emilsson V, Johnson AD, Lee JJ, de Leeuw C, Marioni RE, Medland SE, Miller MB, Rostapshova O, et al. (2014) Common genetic variants associated with cognitive performance identified using the proxy-phenotype method. Proc Natl Acad Sci U S A 111:13790-13794. CrossRef

Schmerr MS, Schleter DS, Pate M, Nowak FV (2002) Phylogenetic distribution of the preoptic regulatory factor genes. 84th Annual Meeting of the Endocrine Society. Bethesda, MD: The Endocrine Society Press, p. 353.

Schulte EC, Ellwanger DC, Dihanich D, Manzoni C, Stangl K, Schormair B, Graf E, Eck S, Mollenhauer B, Haubenberger D, Pirker W, Zimprich A, Brücke T, Lichtner P, Peters A, et al. (2014) Rare variants in LRRK1 and Parkinson's Disease. Neurogenetics 15:4957. CrossRef Medline

Slyvka Y, Inman SR, Malgor R, Jackson EJ, Yee J, Oshogwemoh O, Adame J, Nowak FV (2009) Protective effects of antioxidantfortified diet on renal function and metabolic profile in obese Zucker rat. Endocrine 35:89-100. CrossRef Medline

Strausberg RL, Feingold EA, Grouse LH, Derge JG, Klausner RD, Collins FS, Wagner L, Shenmen CM, Schuler GD, Altschul SF, Zeeberg B, Buetow KH, Schaefer CF, Bhat NK, Hopkins RF, et al. (2002) Generation and initial analysis of more than 15,000 fulllength human and mouse cDNA sequences. Proc Natl Acad Sci U S A 99:16899-16903. CrossRef Medline

Tcherkezian J, Danek El, Jenna S, Triki I, Lamarche-Vane N (2005) Extracellular signal-regulated kinase 1 interacts with and phosphorylates CdGAP at an important regulatory site. Mol Cell Biol 25:6314-6329. CrossRef Medline

Tcherkezian J, Lamarche-Vane N (2007) Current knowledge of the large RhoGAP family of proteins. Biol Cell 99:67-86. CrossRef Medline

Wang Z. (2011) Role of growth factors on Porf-2 expression. Dissertation. Athens, $\mathrm{OH}$ : Ohio University.

Watahiki A, Waki K, Hayatsu N, Shiraki T, Kondo S, Nakamura M, Sasaki D, Arakawa T, Kawai J, Harbers M, Hayashizaki Y, Carninci P (2004) Libraries enriched for alternatively spliced exons reveal splicing patterns in melanocytes and melanomas. Nat Methods 1:233-239. CrossRef

Welsh CF, Roovers K, Villanueva J, Liu Y, Schwartz MA, Assoian RK (2001) Timing of cyclin D1 expression within G1 phase is controlled by Rho. Nat Cell Biol 3:950-957. CrossRef Medline

Yorimitsu T, Sato K, Takeuchi M (2014) Molecular mechanisms of Sar/Arf GTPases in vesicular trafficking in yeast and plants. Front Plant Sci 5:411-422. CrossRef Medline 
Yu Y, Fuscoe JC, Zhao C, Guo C, Jia M, Qing T, Bannon DI, Lancashire L, Bao W, Du T, Luo H, Su Z, Jones WD, Moland CL, Branham WS, et al. (2014) A rat RNA-Seq transcriptomic BodyMap across 11 organs and 4 developmental stages. Nat Commun 5:3230. CrossRef Medline

Yue F, Cheng Y, Breschi A, Vierstra J, Wu W, Ryba T, Sandstrom R, Ma Z, Davis C, Pope BD, Shen Y, Pervouchine DD, Djebali S,
Thurman RE, Kaul R, Rynes E, et al. (2014) A comparative encyclopedia of DNA elements in the mouse genome. Nature 515:35564. CrossRef Medline

Zhen Z-G, Ren S-H, Ji H-M, Ma J-H, Ding X-M, Feng F-Q, Chen S-L, Zou P, Ren J-R, Jia L (2017) Linarin suppresses glioma through inhibition of NF- $\kappa \mathrm{B} / \mathrm{p} 65$ and up-regulating p53 expression in vitro and in vivo. Biomed Pharmacother 95:363-374. CrossRef 